\title{
On form and function of politeness formulae
}

\author{
KATRIN SCHLUND
}

\begin{abstract}
This paper focuses on the notion of politeness formulae as an analytical category in linguistic politeness research. It argues that the current theories of linguistic politeness have neglected the notion of politeness formulae, either ignoring the relationship between their semantic, formal and pragmatic characteristics or disputing their existence altogether, claiming that the emergence of polite meanings is restricted to singular and concrete contexts. It will be shown, however, that a non-contextual approach to linguistic politeness makes it possible to describe politeness formulae systematically on a pragmatic, semantic, and even formal level. The approach is based on the common ground of all politeness phenomena, namely their function of establishing, maintaining or negotiating relations of social distance.
\end{abstract}

Keywords: linguistic politeness, politeness formulae, function of politeness

\section{Introduction}

The title of the present article makes two assumptions which are far from being unquestioned in linguistic politeness theory: 1 . There is such a thing as politeness formulae, i.e., recurring linguistic elements that are stereotypically associated with the communication of polite meanings. 2 . Those formulae can - at least within a given language - be described and classified (semantically, formally and pragmatically) on a functional basis.

As for the first statement, it is important to point out that the existence of politeness formulae is conceived of as not being restricted to their actual occurrence in natural speech, nor to the actual polite intention of the speaker or the hearer's interpretation as polite. It is assumed, on the contrary, that politeness formulae exist independently of concrete contexts.

If it is true that polite linguistic formulae transmit polite meanings independently of concrete contexts, they must consist of specific linguistic means ${ }^{1}$ that indicate their polite content. It is undisputed that linguistic politeness has something to do with recurring, conventionalized linguistic elements. If this were not the case, interlocutors would have a hard time meeting with their everyday (polite) linguistic needs in recurring situations. Even more bothering, yet banal at first glance, is the fact that if linguistic politeness were not formulaic, interlocutors would have no possibility to conventionally implicate and communicate their polite intentions. 
If the linguistic expression of politeness is - at least to a considerable extent - not restricted to particular realisations within a concrete communicative event, one should ask what kinds of linguistic means are used to express politeness. Indeed, one will find that some linguistic means are more likely to occur as instantiations of polite meanings than others. Conventionalized realisations of linguistic politeness will be called politeness formulae. But how can we distinguish an idiomatic expression from a polite idiomatic expression, i.e. a politeness formula? In other words, what is it that makes a linguistic formula a politeness formula? Linguistic politeness theory hardly ever raises this question explicitly and awards it due attention.

To fill this gap, it will be necessary to find a way of systematically describing politeness formulae on semantic, formal and pragmatic grounds. It is argued here that this can be achieved on the basis of the function of politeness. As will be shown later, one of the major functions of politeness is the establishment, maintenance, and negotiation of social distance relations.

Before addressing the assumptions made above in more detail, it is worthwhile discussing the best known linguistic politeness theories in regard to their handling of the issues raised here.

\section{The normative or traditional approach ${ }^{2}$}

What is referred to here as the normative approach very often does not play a major role in overviews of linguistic politeness theories. The reason for this neglect is partly due to the fact that the normative view stands for a rather old-fashioned concept of politeness, namely that politeness is a set of socially stipulated, culture-specific norms of behaviour. However, the idea that politeness is a system of conventionally determined norms is intuitively plausible and based on an unscientific, lay concept of politeness. As the normative approach considers politeness formulae to be the linguistic implementation of social rules, the existence of politeness formulae is taken for granted and neither questioned nor explicitly asserted. Norms of social behavior are simply assumed to result in a certain set of recurring linguistic means (i.e. politeness formulae) to implement those norms. That is the reason why Held (2005 [1992]: 136) refers to this viewpoint as "causal-deterministic". Werkhofer (2005 [1992]: 157) calls this notion of politeness the "traditional view", Fraser (1990) describes the characteristics of the "social norm view" as follows: "Briefly stated, it [the social norm view, KS] assumes that each society has a particular set of social norms consisting of more or less explicit rules that prescribe a certain behavior [...]" (Fraser 1990: 220).

Although normative aspects should be essential to any theory of politeness, linguistic politeness research followed other paths that had been opened up by linguistic pragmatics in the 1960s and 1970s. The normative approach is usually held only implicitly by grammar books that deal with linguistic aspects of politeness within the subchapter of some grammatical category (e.g. the verbal modes or pronominal address). Although the normative concept is not linked to any particular 
names and has produced no research tradition, it is important to mention it here.

First, the traditional view most clearly establishes the link between idiomaticity and politeness because it focuses on the social nature of politeness phenomena. As social norms are by nature shared collectively (otherwise they would be only individual norms and could thus not be recognized as such by the community), they must inevitably be instantiated by recurring linguistic patterns. Politeness is, in the traditional view, anticipated by the interlocutors and most clearly associated with formality, appropriateness, "good" behaviour and other evaluative lay notions of politeness. Thus, the normative approach has no reason either to restrict linguistic politeness to manifestations in concrete contexts or to deny the existence of politeness formulae altogether. As already said, it rather takes politeness as a regular communicative goal and deals with it as a part of the connotative meaning of certain linguistic categories, such as verbal modes, tense, aspect, pronominal address, modal adverbs, particles, nominal derivations (e.g. diminutives), sentence types, formulaic expressions (e.g. greetings, expressions of gratitude), and the like. Its method can therefore be considered deductive: the normative approach towards politeness in language starts from the linguistic structure/device and ascribes a certain polite meaning to it. The problem with this procedure is that almost any of those devices can also be used in contexts in which politeness is not an issue at all. For example, it is not always polite to say please, to ask a question, to use the subjunctive or passive voice or, in Slavonic languages, to employ the perfective aspect.

\section{The pragmatic approach}

The term pragmatic approach ${ }^{3}$ refers to the first linguistic theories of politeness that developed on the grounds of Speech Act Theory (Austin 1962) and the Theory of Implicature (Grice 1975). Austin's view of speech as social action made it possible to integrate politeness phenomena into linguistic pragmatics as an aspect of certain speech acts. Grice's theory of Conversational Implicature gave rise to the idea that politeness should be described in terms of conversational maxims. In the following, a brief outline will be given of the central assumptions and the most important exponents of the pragmatic view ${ }^{4}$.

The first to mention here is Robin Lakoff $\left(1973^{5}, 1975,1979\right)$, whose original aim was to establish pragmatic rules that would operate alongside the syntactic rules postulated by generative linguistics. She did so by juxtaposing a politeness principle to the Gricean maxims, arguing that in most cases in which the Gricean maxims were violated, this was done in order to abide by the maxim of politeness. As Lakoff is not aiming at conducting empirical research but at formulating a theory that can account for the violation of the Gricean maxims and that will identify pragmatic rules of competence, it is self-evident that she does not engage in providing terminological and methodological tools for investigating given instances of speech in regard to the occurrence and make-up of politeness devices. She does, however, at least implicitly 
assume that there must be certain linguistic means by which the three rules can be accounted for in verbal communication, for otherwise the maxim of politeness could not be implemented through language.

Geoffrey Leech's approach $(1977,1980,1983)$ is somewhat more sophisticated and embedded in a general theory of pragmatics. Like Lakoff, Leech (1983) assumes a politeness principle operating alongside Grice's cooperation principle and consisting of several politeness maxims. What is essential in Leech's concept is the assumption that degrees of politeness can be measured by value scales, such as, for instance, an indirectness scale, a cost-benefit scale and a social distance scale. Politeness appears thus to be a gradable characteristic of certain types of speech acts.

The most famous and most frequently applied approach to linguistic politeness is indisputably Brown and Levinson's $(1978,1987)$ face-theory. Like Lakoff and Leech, Brown and Levinson start from the assumption that Grice's theory is basically right and view politeness as a major reason for deviation from the conversational maxims. Face is seen as a twofold aspect of human identity, namely positive and negative face: positive face refers to the fact that individuals need to be integrated and accepted by the community, negative face relates to the individual's wants that her/his actions be unimpeded by the community (cf. Brown and Levinson [1987: 129]). Brown and Levinson regard human interaction as potentially face-threatening - and politeness as a means to reduce that threat. Although their original model includes five different politeness strategies, it is the twofold typology of positive and negative politeness that has proved most fruitful. Positive politeness refers to the politeness efforts that are directed at the interlocutor's positive face wants; negative politeness is in return paid to the negative face of the interactants. The importance of the distinction between positive and negative politeness for linguistic politeness theory will be discussed in more detail in Section 4.

As regards the issues addressed in this paper, the pragmatic theories are characterized by a rather uncritical and unconscious attitude. The authors usually give examples and/or compilations of allegedly polite communicative strategies and rank them as more or less polite. This proceeding betrays the fact that the pragmatic approaches implicitly assume the existence of context-independent polite meanings. However, this attitude is not overtly discussed and remains restricted to the idea of politeness strategies which are heterogeneously implemented by certain stylistic devices, different communicative genres, kinds of speech acts, use of certain linguistic forms, etc. Accordingly, the second issue, the question of how politeness formulae are structured, is not addressed at all. As the notion of "politeness strategies" remains rather unspecified and is inconsistently applied both to speakers' communicative strategies (e.g. be indirect) and to the linguistic means by which these strategies can be implemented (e.g. use downgraders), the pragmatic approaches do not distinguish appropriately between those two things and consequently do not focus on the relationship between them.

In sum, one can say that the normative and pragmatic approach start from opposite points, but come up with the same result. The nor- 
mative approach starts from the linguistic means and attributes polite meanings to them. The pragmatic approach, on the contrary, departs from abstract speaker's strategies of politeness and attributes certain linguistic means to them. Both trains of thought result in the assumption (be it explicit or implicit) that phenomena of linguistic politeness can be described context-independently and that linguistic politeness is shaped by specific linguistic means. It is claimed here that both assumptions are essentially correct. The normative and pragmatic approaches' mistake lies in the fact that they are not concious of their assumptions, which makes them blind to the consequences thereof. As already pointed out above, both the normative and pragmatic view fail to explain why any of their allegedly polite means can also be employed for completely different communicative purposes ${ }^{6}$. Accordingly, they fail to establish a stringent notion of politeness formulae and to develop a theoretical framework to analyse them systematically.

\section{The post-pragmatic approach}

Post-pragmatic theory on linguistic politeness is most prominently represented by Richard J. Watts (e.g. 2004 [2003], 2005), other adherents are Sara Mills (2003) and Miriam Locher (2004; Locher and Watts 2005). It is characterized by its dynamic view of politeness, thus emphasizing the fact that politeness is not only anticipated ex ante (normative view) or only inferred ex post (pragmatic view), but also negotiated in situ by both speaker and hearer. The dynamic notion of politeness in the post-pragmatic model is clearly opposed to the rather static norm- and strategy-based concepts of politeness. It is due to the discursive and disputable nature of politeness that post-pragmatic theorizing has come to the conclusion that linguistic structures are not and cannot be polite in themselves. In other words, politeness formulae do not exist. This attitude is clearly reflected in the fact that Watts (2004 [2003]) only refers to the existence of conventionalized linguistic patterns as "expressions of procedural meaning" (2004 [2003]: 180) which are "open to the attribution of politeness" " (2004 [2003]: 217). The politeness of linguistic structures is, on the contrary, conceived of as a potential interpretation of the hearer; polite meanings are, in other words, dependent on the evaluation of interlocutors in certain and singular speech events. While this assumption may be suitable on the grounds of a general theory of social practice, it is unsatisfying in linguistic terms. This is so because it fails to establish categories by which incidences of linguistic politeness can be investigated. By reducing politeness to the realm of concrete and, therefore, varying contexts, it becomes impossible to do linguistic politeness research on a meso- or macro-level of analysis $\left(\right.$ Terkourafi $2005^{8}$ ). From the post-pragmatic point of view, politeness phenomena can be described linguistically only in terms of conversation analysis, which is, by definition, a micro-level approach. Although it is both necessary and highly promising to investigate the discursive construction and negotiation of polite meanings in authentic communication, the discursive approach of post-pragmatic theory leaves linguistic politeness researchers who want to make assumptions about the 
systematics of linguistic politeness practically empty-handed: as politeness is designed as a possible aspect of concrete utterances, it becomes nearly impossible to establish linguistically based intercultural comparisons of politeness standards. It is, by the way, due to this lack of macro-level applicability that empirical politeness research is still dominated by pragmatic theory, especially by the framework of Brown and Levinson.

The post-pragmatic view has, however, still one big advantage over the other politeness theories. It has succeeded in overcoming a great theoretical problem of politeness theory, namely the antithesis between social and individual aspects of politeness. While the other approaches had been focusing on either the social-prescriptive (normative view) or the individual-creative (pragmatic view) aspect of politeness, post-pragmatic theory holds that politeness actually mediates between the social and the individual, i.e. that it is a means of organizing, maintaining and negotiating interpersonal relationships. It will be shown below that it is on the basis of this function of politeness that a systematic analysis of linguistic politeness can be established.

\section{The function of politeness}

All three approaches ignore the question of what makes a linguistic formula a politeness formula: the normative and pragmatic approaches do not recognize the importance of the question but simply take the polite meanings of "polite linguistic means" or, respectively, "politeness strategies", as a given. The post-pragmatic approach, on the other hand, deals with the problem but comes to the disputable conclusion that there is actually no link between linguistic means and the polite meanings they are attached to in actual speech. Consequently, any linguistic device can - under particular circumstances - be considered polite, which means that there is no way to make general assumptions about the structure and make-up of politeness devices in a given language. That, again, results in the denial of the existence of politeness formulae altogether.

Let us now try to refute the Wittgensteinian notion of the absolute context relativity of polite meanings. Although it is widely accepted that contexts plays a decisive role in the assessment of linguistic politeness phenomena, native speakers of a given language usually find it quite easy to classify sentences according to their degree of politeness without asking for any further contextual information ${ }^{9}$. Furthermore, it is highly plausible that an utterance like "could I have some water, please" is usually considered more polite than "give me some water". It has been argued by the opponents of the non-contextual approach that there can be found (or rather, invented) contexts in which "could I have some water, please" is not interpreted or/and intended as polite. For example, a person $\mathrm{P}$ could utter this sentence in a situation where it will be interpreted as rather impolite, e.g. when her/his interlocutor is highly busy (obviously too busy to comply to P's request) or in a higher-ranking position (and therefore expects $\mathrm{P}$ to get her/his water herself/himself). Or else, it could be that $\mathrm{P}$ simply utters the sentence with an unfriendly, maybe even angry intonation (maybe because s/he has already asked a number of 
times). Of course, all of these circumstances may well occur in natural communication. However, they are specific and rather improbable ${ }^{10}$. In the same vein, the post-pragmatic approach argues that expressions of rudeness can appear to be non-rude in certain situations, e.g. among close friends. Still those instantiations of fake-rudeness would hardly be attached the label "polite" by any of the interlocutors.

To resolve this problem, theorists who support the idea of contextual independence of polite meanings have introduced the notion of abstract context (Escandell-Vidal 1996: 643). Abstract contexts are grounded in the individual's experience and knowledge of how a given situation is usually dealt with. In cases where further contextual information is absent, individuals tend to interpret the situation as a default situation in which the given utterance is stereotypically produced. This proceeding is plausible and apt to account for the empirical finding that individuals are capable of ranking statements according to the degree of politeness without any detailed contextual information.

However, the concept of default contexts could be correct even if politeness formulae were politeness formulae simply because of convention. Regardless of the structural make-up of politeness devices, the speakers of a given language would simply learn and thus know that certain linguistic patterns are usually to be interpreted as polite in a stereotypical situation.

If this were the case, there would be no basis (nor a real reason) to investigate the formal and semantic characteristics of linguistic politeness devices and the relationship between those two dimensions and pragmatic variables. However, the range of linguistic means that are - even across languages - associated with the expression of politeness does not seem to be completely random and merely conventional. On the contrary, it seems that some linguistic means are more likely to perform politeness duties than others. While it is less questionable that politeness formulae are motivated semantically (for example, the salutation goodbye goes back to God be with you, in which the semantic motivation was still manifest) and pragmatically (by the situation in which they occur), the motivation for the use of certain linguistic forms is somewhat less obvious. It is exactly this threefold motivation of politeness formulae that linguistic politeness should engage in because it promises to provide insights into the interrelation of extra-linguistic, cultural motivations and linguistic, structural motivations of linguistic politeness phenomena. Such an analysis could eventually lead to conclusions about potential universalities in linguistic politeness.

To my knowledge, the only theory of linguistic politeness to really focus on the problem of the interrelation between polite contents and politeness structures was formulated by Ehrhardt (2002). Ehrhardt discusses normative and pragmatic theories and argues that they both implicitly assume a relationship between linguistic forms and polite contents. Although in his view this is essentially correct, he holds that both accounts fail to explicitly investigate that relationship by asking the question of why some linguistic forms are more likely to be used for politeness matters than others. After examining some phenomena that are of a traditional interest to politeness studies such as pronominal address, 
verbal modes, tenses and particles, he concludes that the reason why those means are an essential part of politeness studies is to be found in both their literal meaning (which is metaphorically extended for politeness purposes) and in the concrete contexts in which they occur (Ehrhardt 2002: 198). He thus tries to reconcile the contextual and the non-contextual approach.

Ehrhardt (2002: 221) also introduces the notion of 'Höflichkeitsindikator' ('politeness indicator"). Politeness indicators are the formal linguistic means that constitute politeness formulae. It is important to note that politeness indicators are linguistic categories (grammatical categories, for example) that can be part of politeness formulae. However, politeness indicators may in other circumstances just as well be ordinary expressions of tense, mode, other modal meanings, etc., or serve other communicative purposes than politeness (the expression of real uncertainty, anger, affection, and the like). In cognitivist and functionalist terms, this view can be illustrated by the notion of radial categories, i.e. categories that consist of a rather stable centre with fuzzy boundaries on their periphery. In most cases, the polite aspect of the category will be centred towards the periphery, while in some cases it may even be considered the very core of it (consider, for instance, the particle please, which stereotypically functions as a politeness particle).

As Ehrhardt's approach is basically theoretical, he does not engage in developing a tool for empirical studies of linguistic politeness. He does nevertheless give us a few hints of how such a tool could be conceived by pointing out the major function of politeness as a means of conducting cooperative relational work ${ }^{11}$. Ehrhardt (2002: 237) even notes that the only valid basis for investigating linguistic politeness phenomena lies in that common function.

To exploit the notion of relational work in politeness research fruitfully, it is necessary to identify the role that politeness performs in relational work in more detail. As will be shown in the next section, politeness research has already provided an answer to this question.

In linguistic theorizing on politeness, the idea that politeness has the function of regulating interpersonal relations actually is not new. However, before the emergence of the post-pragmatic theories (among which we can now count Ehrhardt's contribution, too) the central function of politeness was usually only hinted at more or less obviously. According to Ehrhardt (2002: 237), it is argued here that politeness phenomena can only be described on the basis of that function as this seems to be their only common denominator. That is why it is promising to take a closer look at that function.

First of all, it needs to be pointed out that the kind of relational work that politeness engages in is essentially social, i.e. that politeness operates on the level of social relations (not or at least to a greatly lesser extent, for example, in intimate ones, where other and less regulated pragmatic parameters than politeness come into play). This aspect is neglected even by the post-pragmatic approaches to politeness. The relational work performed by politeness devices can thus also be referred to as the regulation of relations of social distance. This is, however, a 
metaphor, as distance in politeness formulae can be conceived of only in a non-literal sense.

Reading through both older and more recent contributions to linguistic politeness theory, we find that thoughts about the distancing function of politeness are almost omnipresent. For a start, consider Brown and Levinson's distinction between positive and negative politeness. The two terms actually refer to the function of politeness either to overcome (positive politeness) or to establish or maintain (negative politeness) social distance. The fact that it was those two of Brown and Levinson's original five types of politeness strategies that earned most attention is probably not accidental. There are a number of dual typologies that can be interpreted analogously to Brown's and Levinson's: Scollon and Scollon (1981) refer to "strategies of involvement and independence", Rathmayr (1996) introduces the distinction between "Solidaritäts- und Distanzhöflichkeit" ("politeness of solidarity" and "politeness of distance"), Ehlich (2005: 82-89) talks about the metaphorical use of kinship terms to overcome social distance. In House (2005: 18), the distinction between two basic human needs, namely "coming together" versus "noli me tangere" can be found. Nekvapil and Neustupný state that

The central theme of politeness is how sociocultural distance between interactants is reflected in communication and how it is shaped by it. (Nekvapil and Neustupný 2005: 247-248)

But even before Brown and Levinson, the presence of the distance metaphor is striking. Brown and Gilman (1960) introduce a duality of "power and solidarity" in their famous study on pronominal address. And Lakoff's (1973) rules of politeness can be interpreted in the same vein as well: The rules don't impose and give options can be seen as payment to negative face wants, be friendly considers positive ones.

It is now necessary to focus on the notion of metaphor. For a real metaphor it is essential that relations are not only transferred from one dimension of experience to another (in our case, spatial relations are used to characterize social relations), but that new meanings are attached to those relations. In our case, it seems plausible that distance and closeness are attached to certain value systems, and that those values are culturespecific. Insights of modern cognitive linguistics help us understand the process of attaching meaning to metaphors ${ }^{12}$. Distance can most plausibly be associated with difference, for things at a distance are very often different from us (or, at least, not accessible to our senses to be figured out as different or similar and therefore conceived of as different rather than similar). In a second step, distance/difference may be associated with strangeness and unfamiliarity. Analogously, closeness is in our world linked to similarity and familiarity. The illustration of social relations as a spatially motivated metaphor makes it possible to understand why both positive and negative values can be attached to both distancing and proximity devices in different cultures. The classification of cultures according to their favoring distance or closeness is exactly what has been done in a lot of empirical and comparative intercultural studies on 
politeness (e.g. Sifianou 1992; Pavlidou 1994; Wierzbicka 1985; Rathmayr 1996a, 1996b; Schlund 2009).

The above statements have served to establish the regulation of social distance relations as a central function of politeness. By referring to the concept of metaphor, it has been argued that the major function of politeness, i.e. the regulation of social relationships, was to be interpreted as a means of establishing closeness and distance between individuals. Both closeness and distance are culturally determined concepts that are associated with certain, but different, culture-specific positive and negative values. Closeness, as associated with similarity and familiarity, can thus be loaded with positive connotations in one culture (e.g. intimacy, sincerity) while another culture most positively values distance as a way of accounting for individuality and variety. It can further be assumed that the distancing preferences of a given culture will be reflected in the pragmatic, semantic and formal make-up of the linguistic politeness devices that this culture produces. To test this assumption, it will be necessary to find a method of analysis that will enable us to determine whether a given linguistic means is to be classified as a device of distance or closeness.

One further remark needs to be made about distance. While there is naturally only one dimension of closeness, two dimensions of distance are possible. Horizontal distance refers to the distance relation between equal interlocutors, vertical distance, on the other hand, refers to hierarchical social relations. Although not made in all the politeness theories mentioned above, this is a very important point. Lakoff (1975), for instance, accounts for this fact with her threefold typology of camaraderie, distance and deference cultures.

After showing that the distinction between politeness of closeness and politeness of distance is well-motivated and justified, we can now pass to the question of what the functionalist method of analysis proposed here could be like.

\section{Functional analysis of politeness formulae}

Before demonstrating the functional analysis advocated here, we need to focus on the notion of politeness formula. Up to now, the term has been used without any further explanation in this article, the assumption being that the reader has a common sense understanding of the word that is sufficient to follow the lines of argumentation.

As has already been pointed out, the expression of linguistic politeness is to a great extent linked to idiomaticity and convention. This is even more the case on the macro-level of analysis, on which, by definition, only idiomatic and conventionalized elements (i.e., recurring elements) can be accounted for. All formulaic expressions which are stereotypically used as a means to conduct social relational work cooperatively can be called politeness formulae ${ }^{13}$. A politeness formula can be fully formulaic or only semi-formulaic ${ }^{14}$, and it can consist of one single world or a whole sentence (examples will be given later on in this section). Any other linguistic means that will not stereotypically, but only 
occasionally be used as a politeness device on a meso- or micro-level of analysis will be referred to as a politeness form.

A further comment needs to be made on the link between politeness formulae and politeness indicators. Politeness formulae are (often, not always) made up of politeness indicators, i.e. linguistic means that are suited to indicate polite meanings. As a major function of politeness is to reflect relations of social distance, it is argued that politeness indicators (and, consequently, politeness formulae) can be classified according to their metaphorical distancing or nearing potential. The metaphorical potential of politeness formulae can be examined in three dimensions: the formal, semantic and pragmatic dimensions. The pragmatic dimension asks for the circumstances under which a politeness formula is usually employed. In the case of apologies, it is important to ask in which situations a culture expects the apologizing formula to occur. Pragmatic variables such as the degree of norm-violation that preceded the apology, the hierarchy between the interlocutors, etc., have to be considered here to interpret the pragmatic factor in regard to its distancing or nearing potential. The semantic dimension is concerned with the semantics of the formula, even if they have been obscured by processes of pragmaticalisation. The German requesting formula bitte ('please') has developed from ich bitte dich/Sie (literally: 'I am begging you'), which can be interpreted as a means of deference, thus originally metaphorizing vertical distance. The most interesting, and probably mostly disputed, dimension of analysis is the formal dimension. In accordance with Ehrhardt (2002), it is assumed here that some linguistic forms are more suitable to indicate politeness than others. The relation assumed between the content and form of politeness formulae is thus one of iconicity: distancing devices will reflect distance on a formal level, and nearing devices will reflect closeness on a formal level, respectively. The stereotype semi-formulaic politeness formula to utter a request in a service encounter is 'I would like' + direct object. This formula consists of two formal politeness indicators, namely the verbal mode subjunctive and the sentence focus on ego (and not, as in other languages in comparable situations, on alter). Both indicators can in our model be interpreted as distancing devices. The following table was designed to illustrate this method of analysis.

\begin{tabular}{|l|l|l|l|}
\hline $\begin{array}{l}\text { Dimension of } \\
\text { analysis }\end{array}$ & formal & semantic & pragmatic \\
\cline { 2 - 4 } & $\begin{array}{l}\text { What is the formal } \\
\text { make-up of the } \\
\text { formula, which } \\
\text { morphological } \\
\text { and/or syntactic } \\
\text { means are used? }\end{array}$ & $\begin{array}{l}\text { What is the } \\
\text { content of the } \\
\text { constituents of the }\end{array}$ & $\begin{array}{l}\text { In which situations } \\
\text { does the PF occur? } \\
\text { By whom is it used } \\
\text { and towards } \\
\text { whom? }\end{array}$ \\
\hline
\end{tabular}

It may occur that for a given politeness formula, it is not promising to conduct the analysis on all three levels. In the case of one-word formulae, formal analysis may be unfruitful; in the case of fully pragmaticalized formulae a semantic analysis seems less promising. However, if the assumptions made above are correct, functional analysis will work on at least one level of analysis. 


\section{Conclusion: what the functional perspective can add to theory and empirical research}

The aim of this contribution was not to introduce another theory of linguistic politeness but to add a new perspective to the already existing theories. It was argued that the major function of politeness existed in the maintenance and regulation of social distance, an account consistent not only with post-pragmatic but also with pragmatic theorizing. To justify this view, the metaphorical motivation of social distance was discussed, showing that distance relations are metaphorically attached to cultural values and that linguistic politeness reflects those values. In a second line of thought, it was argued that politeness research should not be reduced to studies of singular incidents of natural speech but that politeness should be accounted for on a macro-level of analysis first, with politeness formulae being the main category of analysis. The notion of the absolute context relativity of linguistic politeness was thus replaced by the notion of abstract contexts (Escandell-Vidal 1996). It was then argued that the make-up of politeness formulae was motivated functionally, i.e. by the distancing function that was assumed to be central for politeness in the first place. The functional motivation was expected to be traceable not only on the pragmatic and semantic, but also on the formal level of analysis. The inclusion of the formal level was of major importance as it is shown on this level that linguistic means that constitute politeness formulae are not arbitrary but motivated. E.g., the passive voice can be functionalized for politeness purposes because it is a means of changing the focus of an utterance; verbal modes, adverbial modifiers and particles can be functionalized because they seemingly transfer the proposition of an utterance into the realm of potentiality; the perfective verbal aspect (in Slavonic languages) focuses on the semelfactive nature of an action, etc. It is basically on the formal level that the question of why some linguistic structures seem to be more closely attached to politeness than others can be answered ${ }^{15}$.

The method advocated here is probably not the only way to describe PF systematically. However, an advantage of the functional account lies in the fact that it aims at including all kinds of phenomena associated with linguistic politeness research (e.g., forms of address, greetings, apologies, requests) that are usually treated separately in linguistic politeness research. Second, the functional perspective is not merely descriptive. By linking the pragmatic, semantic and formal makeup of politeness devices with cultural value systems, an explanative aspect is added to the description. The contribution that studies on linguistic politeness can make to the vast field of cultural studies thus becomes even more manifest. Finally, the functional perspective allows for an explanation of why the formal make-up of politeness formulae is dominated by (usually the marked member of) certain categories while others do not play a stereotypical role here. Although not "polite in themselves", those linguistic categories add to the "politeness default value" (Escandell-Vidal 1996: 643) ascribed to the politeness formulae 
that they are a part of. As such, they must be acknowledged the status of an object of investigation in any empirical study on linguistic politeness.

\section{Notes}

${ }^{1}$ The word means is used here in a most general sense, referring to semantic, formal and pragmatic aspects of the linguistic inventory.

${ }^{2}$ The labels given to the different approaches to linguistic politeness here must not be confused with the labels given elsewhere. For instance, Terkourafi (2005) does not discuss what is called the normative or traditional approach here, but refers to the Gricean paradigm as "traditional" instead. The Gricean accounts, however, are here referred to as "pragmatic accounts".

${ }^{3}$ Remember that the pragmatic approach corresponds to the "traditional view" in Terkourafi's terms (2005).

${ }^{4}$ The interested reader is referred to one of the numerous overviews of the different streams of thought in linguistic politeness theory. A succinct, yet highly informative survey of both the pragmatic (traditional) and the post-pragmatic (modern) view of politeness can be found in Terkourafi (2005). For other overviews consult Fraser (1990); Held (2005 [1992]); Watts (2004: 47-116, 2005: xi-xlvii).

${ }^{5}$ As Grice's ideas had been known in linguistic circles since the end of the 1960ies, Lakoff could base her thoughts on Grice as early as 1973, well before the official publication of his article in 1975 (cf. Watts 2005: xxxiv).

${ }^{6}$ The discussion betrays once again the western ethnocentricity of politeness theory. Of course there are some languages in which politeness matters actually are grammaticalized (e.g. Japenese). As those languages are not European, they tend to be ignored by western mainstream research. Nevertheless, it holds for the languages of the western hemisphere that politeness is not a grammaticalized category and that, even in languages where it is, a lot about politeness remains open to concrete intentions and interpretations.

${ }^{7}$ In the original, Watts talks about "politeness", by which he means lay interpretations of politeness.

While Terkourafi (2005) holds that approaches to politeness on any level of granularity (i.e. macro-, meso- and micro-level) are equal, I assume a hierarchic order between the three levels. As the macro-level analysis serves as the basis for the lower levels, it must be considered superordinate to them.

${ }^{9}$ A survey on linguistic politeness in Serbian and German, carried out among German and Serbian native speakers, supports this assumption: all of the 120 participants addressed the question in which they were asked to rank propositionally identical sentences with regard to their degree of politeness and did not seem to have any particular difficulties with their task (cf. Schlund 2009: 92-101).

${ }^{10}$ A special point has to be made about irony. Irony states, by definition, the contrary of the speaker's actual intention. As such, the ironic use of linguistic means could serve as a counter-example for anything and can thus not be offered as evidence of the contextual approach to politeness, either.

${ }^{11}$ To my knowledge, Ehrhardt (2002) actually was the first to conceive of politeness as a medium of relational work. Watts, who is usually considered the creator of the concept, developed his view one year later. The reason why Ehrhardt's contribution did not receive wide attention in international linguistic politeness research is probably due to the fact that he published only one monograph on the topic, and that the language of the monograph is German. The fact that two researchers formulated two very similar theories of politeness independently of each other even increases the plausibility of their concept.

${ }^{12}$ For further information on the cognitive linguistic framework cf. Janda (2006).

${ }^{13}$ Of course, address forms also belong to the realm of politeness formulae as they represent the highly conventionalized usage of nominal and pronominal forms. 


\begin{abstract}
14 The similarity to Watt's (2003: 186-200) distinction between formulaic and semiformulaic expressions of procedural meaning is obvious. The differences between the two kinds of politeness formulae and the two kinds of expressions of procedural meanings are that politeness formulae exist independently of their actual use in natural speech, and, consequently, that it is possible to compile an inventory of the most current politeness formulae of a given language.

${ }^{15} \mathrm{It}$ is worth noting here that it is usually the marked member of a category that is assigned a "polite potential" (e.g. past and future tenses, passive voice, modes other than indicative, perfective aspect). This is probably due to the characteristic of politeness as some kind of extra-payment to the interpersonal function of language.
\end{abstract}

\title{
References
}

Austin, John (1971 [1962]). How to do things with words. The William James lectures delivered at Harvard University in 1955. Oxford et al.: Oxford University Press.

Brown, Roger and Albert Gilman (1960). The pronouns of power and solidarity. In: Sebeok, Thomas A. (ed.), Style in language, 253-276. London et al.: John Wiley \& Sons, Inc.

Brown, Penelope and Stephen C. Levinson (1978). Universals in language usage: politeness phenomena. In: Goody, Esther (ed.), Questions and politeness: strategies in social interaction, 56-289. Cambridge et al.: Cambridge University Press.

Brown, Penelope and Stephen C. Levinson (1987). Politeness. Some universals of language usage. Cambridge: University Press.

Fraser, Bruce (1990). Perspectives on politeness. Journal of Pragmatics 14. 219-236.

Ehlich, Konrad (2005 [1992]). On the historicity of politeness. In: Konrad Ehlich, Richard J. Watts \& Sachiko Ide (eds.), Politeness in language. Studies in its history, theory and practice. 2nd edn., (Trends in linguistics. Studies and monographs 59), 71-107. Berlin et al.: de Gruyter.

Ehrhardt, Claus (2002). Beziehungsgestaltung und Rationalität. Eine linguistische Theorie der Höflichkeit. Trieste: Edizioni Parnaso.

Escandell-Vidal, Victoria (1996). Towards a cognitive approach to politeness. Language Sciences 18. 629-650.

Grice, Herbert Paul (1975). Logic and conversation. In: Peter Cole \& Jerry L. Morgan (eds.), Speech acts (Syntax and semantics 3). 41-58. New York \& San Francisco et al.: Academic Press.

Held, Gudrun (2005 [1992]). Politeness in linguistic research. In: Konrad Ehlich, Richard J. Watts \& Sachiko Ide (eds.), Politeness in language. Studies in its history, theory and practice. 2nd edn. (Trends in linguistics. Studies and monographs 59). 131-151. Berlin et al.: de Gruyter.

House, Juliane (2005). Politeness in Germany: politeness in Germany? In: Leo Hickey, Leo \& Miranda Stewart (eds.), Politeness in Europe. 13-28. Clevedon et al.: Multilingual Matters LTD. 
Janda, Laura (2006). Cognitive linguistics. Glossos 8 (Fall). 1-60. http://www.seelrc.org/glossos/issues/8/janda.pdf (accessed August 13th 2009).

Lakoff, Robin Tolmach (1973). The logic of politeness; or, minding your p's and q's. In: Claudia Corum, Cedric T. Smith-Stark \& Ann Weiser (eds.), Papers from the Ninth Regional Meeting. 292-305. Chicago: Chicago Linguistic Society.

Lakoff, Robin Tolmach (1975). Language and woman's place. New York: Harper and Row.

Lakoff, Robin Tolmach (1979). Stylistic strategies within a grammar of style. In: Judith Orasanu, Mariam Slater \& Leonore Loeb Adler, Language, sex and gender: does "la différence" make a difference? (Annals of the New York Academy of Science, 327). 53-78. New York: New York Academy of Sciences.

Leech, Geoffrey (1977). Language and tact. Amsterdam: Benjamins.

Leech, Geoffrey (1980). Explorations in semantics and pragmatics. Amsterdam: Benjamins.

Leech, Geoffrey (1983). Principles of pragmatics. London et al.: Longman.

Locher, Miriam A. (2004). Power and politeness in action. Disagreements in oral communication. (Language, power and social process 12). Berlin et al.: de Gruyter.

Locher, Miriam A. \& Richard J. Watts (2005). Politeness theory and relational work. In: Journal of Politeness Research 1 (1). 9-33.

Mills, Sara (2003). Gender and Politeness. Cambridge: Cambridge University Press.

Nekvapil, Jiř́ \& Jiř́ V. Neustupný (2005). Politeness in the Czech Republic: distance, levels of expression, management and intercultural contact. In: Leo Hickey, Leo \& Miranda Stewart (eds.), Politeness in Europe. 247-262. Clevedon et al.: Multilingual Matters LTD.

Pavlidou, Theodossia (1994). Contrasting German-Greek politeness and the consequences. In: Journal of Pragmatics 21 (5). 487-511.

Rathmayr, Renate (1996a). Sprachliche Höflichkeit. Am Beispiel expliziter und impliziter Höflichkeit im Russischen. In: Wolfgang Girke (ed.), Referate des XXI. Konstanzer Slavistischen Arbeitstreffens. Mainz 26.-29.09.1995 (Slavistische Beiträge 342). 362-391. München: Sagner.

Rathmayr, Renate (1996b). Höflichkeit als kulturspezifisches Konzept: Russisch im Vergleich. In: Ohnheiser, Ingeborg (ed.), Wechselbeziehungen zwischen slawischen Sprachen, Literaturen und Kulturen in Vergangenheit und Gegenwart. Akten der Tagung aus Anlaß des 25jährigen Bestehens des Instituts für Slawistik an der Universität Innsbruck. Innsbruck, 25. - 27. Mai 1995 (Innsbrucker Beiträge zur Kulturwissenschaft: Slavica Aenipontana 4). 174-185. Innsbruck: Institut für Sprachwissenschaft.

Schlund, Katrin (2009). Genese und Gebrauch von Höflichkeitsformeln im Serbischen und Deutschen. Ein funktionales Modell der Höflichkeit 
und seine Anwendung (Slavistische Beiträge 470). München \& Berlin: Otto Sagner.

Scollon, Suzanne Wong \& Ron Scollon (1981). Intercultural communication. A discourse approach. Oxford UK et al.: Blackwell.

Sifianou, Maria. 1992. Politeness Phenomena in England and Greece. A Cross-cultural Perspective. Oxford: Clarendon Press.

Terkourafi, Marina (2005). Beyond the micro-level in politeness research. Journal of Politeness Research 1 (2): 237-262.

Watts, Richard J. 2004 [2003]. Politeness (Key topics in sociolinguistics 1). Cambridge: Cambridge University Press.

Watts, Richard J. (2005). Linguistic politeness research: quo vadis? In: Konrad Ehlich, Richard J. Watts \& Sachiko Ide (eds.), Politeness in language. Studies in its history, theory and practice. 2nd edn. (Trends in linguistics. Studies and monographs 59). xi-ilvii. Berlin et al.: de Gruyter.

Wierzbicka, Anna (1985). Different cultures, different languages, different speech acts. Polish vs. English. Journal of Pragmatics 9, 145-178. 